\title{
Is the implementation of smoke-free policies at workplaces associated with living in a smoke-free home?: Findings from a national population-based study in Malaysia
}

\author{
Kuang Hock Lim', Hui Li Lim², Chien Huey Teh', Sumarni Mohd Ghazali', Chee Cheong Kee', Pei Pei Heng', Rafiza \\ Shaharuddin', Jia Hui Lim
}

\begin{abstract}
INTRODUCTION Studies have shown that the implementation of smoke-free policies at workplaces have shifted the social norms towards secondhand smoke (SHS) exposure at home. This study aimed to investigate whether working in a smokefree workplace is associated with living in a smoke-free home (SFH).

METHODS The data were derived from the Malaysian Global Adult Tobacco Survey (GATS-M), collected in 2011-2012, involving 4250 respondents. Data analyses involved 1343 respondents reported to be in the working population.

RESULTS More than half of the respondents (58.5\%) were reportedly working in smoke-free workplaces. Almost a quarter (24.8\%) of those who worked in smokefree workplaces stayed in smoke-free homes, which was more than two times higher than their counterparts who worked at non-smoke-free workplaces $(24.8 \%$ vs $12.0 \%, \mathrm{p}<0.001)$. Multivariable analyses further substantiated this finding $(\mathrm{AOR}=2.01,95 \% \mathrm{CI}: 1.11-3.61$, reference group $=$ worked at non-smoke-free workplaces).

CONCLUSIONS This study found an association between living in smoke-free homes and working at smoke-free workplaces, which could suggest a positive impact of implementing smoke-free workplaces.
\end{abstract}

\begin{tabular}{l} 
AFFILIATION \\
1 Institute for Medical \\
Research, Ministry of Health, \\
Kuala Lumpur, Malaysia \\
2 Hospital Sultan Haji Ahmad \\
Shah, Temerloh, Malaysia \\
3 School of Science, Monash \\
University Malaysia, Subang \\
Jaya, Malaysia \\
CORRESPONDENCE TO \\
Kuang Hock Lim. Institute for \\
Medical Research, Ministry \\
of Health, Jalan Pahang, \\
50588 Kuala Lumpur, Wilayah \\
Persekutuan, Malaysia. \\
E-mail: keelimkota@yahoo.com \\
KEYwORDS \\
secondhand smoke, smoke- \\
free home, smoke-free \\
workplace, population-based \\
study, Global Adult Tobacco \\
Survey-Malaysia \\
\hline Received: 7 October 2018 \\
Revised: 12 December 2018 \\
Accepted: 12 December 2018 \\
\end{tabular}

https://doi.org/10.18332/tid/100692 rural dwellers, the younger age group, and those with lower educational attainment. Studies have documented that the exposure to SHS is linked to coronary heart disease, respiratory infections and asthma, as well as a variety of cancers ${ }^{7-9}$. Also, it increases the risk of smoking initiation among nonsmoking adolescents ${ }^{10}$ and reduces the likelihood of smoking cessation among youth smokers ${ }^{11}$. Recognition of such threats has led the Malaysian government to initiate various policies and control measures to address this problem. The Ministry of Health Malaysia had introduced the expansion of 
smoke-free zones in public localities and working areas since $1993^{12}$. Smoking is prohibited at health facilities since 1993, followed by an expansion of smoke-free areas to all government premises, schools and education facilities, including financial institutions such as banks, National Telecom company, National Energy company, and post offices. Smoking is prohibited only on floors with service counters, implying that smoking is permitted on floors with offices but without service counters (provided those floors do not have centralized air-conditioning). In 2009 , smoking was prohibited in all workplaces with a centralized air-conditioning system ${ }^{13}$. Also, indoor workplaces located in smoke-free initiatives areas such as the 'Melaka Bebas Asap Rokok' (Melaka smoke-free initiatives) had also been restricted ${ }^{14}$. The implementation of the smoke-free workplace was supported by frequent visits of enforcement officers to the abovementioned working areas. Furthermore, the National Institute of Occupational Safety and Health, Malaysia, also issued the guidelines of nonsmoking in offices to all employers to enhance indoor air quality in workplaces ${ }^{15}$. However, smoking is still permitted in many types of indoor workplaces, which is not stipulated in the Control of Tobacco Product Regulations.

Various studies have demonstrated a positive relationship between the implementation of smokefree policies at workplaces and living in smoke-free homes in both developed and developing countries. Kaleta et al. ${ }^{16}$ and Lee et al. ${ }^{17}$ reported an adjusted odds ratio (AOR) of 5.3 and 2.07, respectively, in their studies among the Nigerian and Indian populations who worked in smoke-free workplaces and stayed in smoke-free homes, compared to those who worked in places that allowed smoking. Nazar et al. ${ }^{18}$ completed a study in 15 Lower-Middle-Income Countries (LMIC), which also reported identical positive findings with a pool AOR of 1.61. Apart from the significant association between smoke-free policies and living in smoke-free homes, there is also a significant association between living in smoke-free homes and the smoking status of respondents ${ }^{16,18}$, their education levels ${ }^{16,18}$, the residential areas ${ }^{16,18}$, genders ${ }^{16,18}$, types of occupation $^{18}$, and age groups ${ }^{16,18}$. Although a plethora of studies has been carried out to determine the association and causality factors between working in the smoke-free environment and living in smoke-free homes, there was no such study in Malaysia. Therefore, an investigation of the association between working in smoke-free areas and living in smoke-free homes was needed to provide scientific evidence to motivate public health authorities to formulate suitable policies to prohibit smoking in more indoor working areas in Malaysia. This paper aimed to address these gaps and to generate constructive findings to assist health authorities in proposing a comprehensive smoke-free policy in this country.

\section{METHODS}

This study used data from the Malaysian Global Adult Tobacco Survey (GATS-M), which was carried out in Malaysia from 2011 to 2012. The nationwide study of GATS-M employed a cross-sectional study design and multi-stage proportionate to size sampling method to select a representative sample of noninstitutionalized respondents aged 15 years and older. Our survey in Malaysia adopted the methodology and tools suggested in the GATS survey. GATS-M has an overall response rate of $83.1 \%(n=4250 / 5112)$. The sample size of 5112 was based on GATS sampling protocol (in which a sample of at least of 4000 respondents is required; 2000 males and 2000 females with 2000 adults each from the urban and the rural areas). The sample size was then adjusted upward to allow for potential ineligibility and non-response rate. The data obtained were weighted taking into account the complex study design and non-response rate based on the 2010 National Population Census data to ensure its national representativeness. Only respondents who reported to be working within the last 12 months before their interview and working indoors were included in the analysis.

The dependent variable in the study is 'living in smoke-free homes', which was measured by an item 'has anyone smoked inside their home in the past 30 days'. The respondents who answered 'no' were classified as 'living in smoke-free homes' and 'yes' as 'living in non-smoke-free homes'. The independent variable is 'working at smoke-free workplaces'. The categorization of smoke-free policy at working areas was classified as 'total restriction' (smoking is not allowed anywhere in the building) 'partial restriction' (smoking is allowed in certain places in the building) and 'non-restriction' (smoking is allowed everywhere and/or policy to restrict smoking in the working 
areas) was based on individual response, whether their working areas had such restrictions. In addition, smoking status and sociodemographic variables in this study include age group (15-24, 25-44, 45-64, $\geq 65$ years), gender, residence (rural, urban), current use of tobacco products (current smoker, current nonsmoker), education level (below primary school level, below secondary school level, completed secondary and higher secondary school, college/university and above), occupation (government sector, private sector or self-employed), and marital status (married, single, widow(er)/divorced), which were all significantly associated with living in smoke-free homes in previous studies $^{16,18}$.

\section{Statistical analysis}

Data cleaning was performed before analysis. The sample was weighted to represent the general population aged 15 years and older, based on the 2010 Malaysia Population Census, study design and response rate of the study. Descriptive statistics were employed to describe the sociodemographic characteristics of respondents while chi-squared analysis was used to investigate the association between the proportion of respondents who lived in smoke-free homes and working in smoke-free areas, and sociodemographic variables (age, gender, residence, marital status, education attainment, occupation, and smoking status). All univariate analyses with p-values less than 0.25 or those significantly associated with living in smoke-free homes from previous studies were included in the multiple logistic regression model (MLR). Two-way interaction between working in the smoke-free environment and smoking status, working in the smoke-free environment and all sociodemographic variables (age, gender, residence, education attainment, occupation) was carried out to determine possible interaction between the independent variables. A p-value of $>0.05$ indicates that there is no significant interaction between the independent variables. All statistical analyses were carried out at $95 \%$ CI using SPSS statistical software (complex sample design) version 22 .

\section{RESULTS}

A total of 1140 respondents who had worked for 12 months and indoors were included in the analyses. From the 1140 respondents, about two-thirds of the respondents were males (59.0\%). More than threequarters of the respondents resided in urban areas $(80.2 \%)$ and were of age $<45$ years $(80.2 \%)$. More than half $(56.6 \%)$ of the respondents reported that they were working in smoke-free areas and less than one-fifth $(18.8 \%)$ of the respondents reported that they were living in smoke-free homes. Nearly onethird $(28.9 \%)$ of respondents were current smokers (Table 1).

The proportion of respondents living in smokefree homes was slightly higher among respondents

Table 1. Sociodemographic characteristics of respondents aged 15 years and older reporting working in the last 30 days

\begin{tabular}{|c|c|c|c|}
\hline Variable & $\begin{array}{l}\text { Estimated } \\
\text { population }\end{array}$ & Sample & $\%$ \\
\hline \multicolumn{4}{|l|}{$\begin{array}{l}\text { Smoking restriction at working } \\
\text { areas }\end{array}$} \\
\hline None & 700607 & 135 & 11.3 \\
\hline Partial & 1990207 & 345 & 32.1 \\
\hline Total & 3517087 & 632 & 56.6 \\
\hline \multicolumn{4}{|l|}{ Living in smoke-free home } \\
\hline Yes & 639182 & 124 & 18.8 \\
\hline No & 2767464 & 489 & 81.2 \\
\hline \multicolumn{4}{|l|}{ Gender } \\
\hline Male & 3819459 & 668 & 59.0 \\
\hline Female & 2649238 & 416 & 41.0 \\
\hline \multicolumn{4}{|l|}{ Residential } \\
\hline Urban & 5186797 & 726 & 80.2 \\
\hline Rural & 1281901 & 416 & 19.8 \\
\hline \multicolumn{4}{|l|}{ Ethnicity } \\
\hline Malay & 4017473 & 703 & 62.1 \\
\hline Chinese & 1281888 & 208 & 19.8 \\
\hline Indian & 602815 & 82 & 9.3 \\
\hline Others & 566520 & 148 & 9.8 \\
\hline \multicolumn{4}{|l|}{ Age group } \\
\hline $15-24$ & 1428212 & 168 & 22.1 \\
\hline $25-44$ & 3761182 & 691 & 58.1 \\
\hline $45-64$ & 3564736 & 268 & 19.0 \\
\hline$\geq 65$ years & 1603529 & 14 & 0.8 \\
\hline \multicolumn{4}{|l|}{ Education level } \\
\hline Less than primary school & 115180 & 34 & 1.8 \\
\hline Less than secondary school & 1148017 & 207 & 17.9 \\
\hline $\begin{array}{l}\text { Completed secondary or high } \\
\text { school }\end{array}$ & 3564735 & 629 & 55.4 \\
\hline College and above & 1603529 & 269 & 24.9 \\
\hline
\end{tabular}


Table 1. Continued

\begin{tabular}{|c|c|c|c|}
\hline Variable & $\begin{array}{l}\text { Estimated } \\
\text { population }\end{array}$ & Sample & $\%$ \\
\hline \multicolumn{4}{|l|}{ Occupation } \\
\hline Government & 1383699 & 303 & 22.0 \\
\hline Private & 4007207 & 653 & 63.6 \\
\hline Self-employed & 905448 & 168 & 14.4 \\
\hline \multicolumn{4}{|l|}{ Income level } \\
\hline Quintile 5 & 2248135 & 349 & 35.1 \\
\hline Quintile 4 & 1633201 & 301 & 25.5 \\
\hline Quintile 3 & 1348017 & 228 & 21.2 \\
\hline Quintile 2 & 751033 & 148 & 11.9 \\
\hline Quintile 1 & 410762 & 101 & 6.4 \\
\hline \multicolumn{4}{|l|}{ Marital status } \\
\hline Married & 3862405 & 742 & 59.8 \\
\hline Single & 2409918 & 373 & 37.3 \\
\hline Widow(er)/divorced & 190051 & 60 & 2.9 \\
\hline \multicolumn{4}{|l|}{ Smoking status } \\
\hline Yes & 1904566 & 330 & 28.4 \\
\hline No & 4564131 & 811 & 70.6 \\
\hline
\end{tabular}

who reported to be working under partial and total restriction of smoking in workplaces in comparison to respondents whose workplaces allowed smoking practices. Besides, the proportion of respondents living in smoke-free homes was also found to be higher among females, respondents residing in rural areas, of older age groups, those with higher education attainment, higher income quintile groups and current smokers. Multivariable logistic regression demonstrated that the odds of living in smokefree homes was 2 times higher among respondents who were working in partial and total smoke-free environments compared to those who were working in non-smoke-free areas (total smoking restriction, $\mathrm{AOR}=2.93$; 95\% CI: 1.20-7.16; partial restriction, $\mathrm{AOR}=2.58$, 95\% CI: $1.05-6.31$, with non-restriction as the reference). Non-current smokers ( $\mathrm{AOR}=32.26$, 95\% CI: 15.36-66.66) and females (AOR $=2.75 ; 95 \%$ CI: 1.41-4.35) were more likely to live in smoke-free homes than current smokers and males (Table 2).

Table 2. Prevalence and factors associated with living in a smoke-free home among Malaysian working adults percentages and adjusted odds ratios (AORs) are weighted

\begin{tabular}{|c|c|c|c|c|c|c|}
\hline \multirow[t]{2}{*}{ Variable } & \multicolumn{4}{|c|}{ Living in smoke free home } & \multicolumn{2}{|c|}{$\begin{array}{l}\text { Factors associated with } \\
\text { living in smoke free home }\end{array}$} \\
\hline & $\begin{array}{l}\text { Estimated } \\
\text { population }\end{array}$ & Sample & $\%$ & $95^{\circ} \% \mathrm{CI}$ & AOR** & $95 \% \mathrm{CI}$ \\
\hline \multicolumn{7}{|c|}{ Smoking restriction at working areas } \\
\hline None & 75249 & 15 & 16.9 & $9.3-28.6$ & Ref. & Ref. \\
\hline Partial & 245226 & 41 & 19.9 & $13.7-28.0$ & 2.58 & $1.05-6.31$ \\
\hline Total & 292725 & 64 & 19.1 & $14.0-25.5$ & 2.93 & $1.20-7.16$ \\
\hline \multicolumn{7}{|l|}{ Gender } \\
\hline Male & 329421 & 66 & 15.1 & $10.9-20.4$ & Ref. & Ref. \\
\hline Female & 309761 & 58 & 25.4 & 18.9-33.2 & 2.75 & $1.41-4.35$ \\
\hline \multicolumn{7}{|c|}{ Residential } \\
\hline Urban & 463139 & 65 & 17.6 & $13.3-22.9$ & Ref. & Ref. \\
\hline Rural & 176042 & 59 & 22.8 & $16.9-30.0$ & 1.19 & $0.69-2.06$ \\
\hline \multicolumn{7}{|l|}{ Ethnicity } \\
\hline Malay & 419952 & 83 & 18.3 & $13.8-23.7$ & 0.37 & $0.17-0.80$ \\
\hline Chinese & 138655 & 25 & 24.7 & $15.6-36.8$ & Ref. & Ref. \\
\hline Indian & 56472 & 9 & 26.5 & $11.6-49.0$ & 1.01 & $0.27-3.84$ \\
\hline Others & 24102 & 7 & 7.2 & $2.7-18.2$ & 0.36 & $0.12-1.05$ \\
\hline \multicolumn{7}{|l|}{ Age group } \\
\hline $15-24$ & 133710 & 16 & 16.0 & $8.9-27.2$ & Ref. & \\
\hline $25-44$ & 353109 & 76 & 18.0 & 13.8-23.1 & 1.24 & $0.30-3.28$ \\
\hline $45-64$ & 152363 & 32 & 25.6 & $16.4-37.7$ & 3.55 & $2.01-5.28$ \\
\hline$\geq 65$ years & 14615 & 2 & 100 & & & \\
\hline
\end{tabular}


Table 2. continued

\begin{tabular}{|c|c|c|c|c|c|c|}
\hline \multirow[t]{2}{*}{ Variable } & \multicolumn{4}{|c|}{ Living in smoke free home } & \multicolumn{2}{|c|}{$\begin{array}{l}\text { Factors associated with } \\
\text { living in smoke free home }\end{array}$} \\
\hline & $\begin{array}{l}\text { Estimated } \\
\text { population }\end{array}$ & Sample & $\%$ & $95^{\circ} \% \mathrm{CI}$ & AOR** & $95 \% \mathrm{CI}$ \\
\hline \multicolumn{7}{|l|}{ Education level } \\
\hline Less than primary school & 5934 & 2 & 7.1 & $1.5-28.3$ & 0.36 & $0.06-2.28$ \\
\hline Less than secondary school & 102606 & 21 & 16.3 & $9.1-27.4$ & 0.87 & $0.27-2.77$ \\
\hline Completed secondary or high school & 332348 & 68 & 17.1 & $12.7-22.8$ & 1.09 & $0.57-2.09$ \\
\hline College and above & 198239 & 33 & 27.3 & $18.8-38.0$ & Ref. & \\
\hline \multicolumn{7}{|l|}{ Occupation } \\
\hline Government & 191221 & 44 & 29.6 & $20.7-40.4$ & Ref. & \\
\hline Private & 354373 & 66 & 16.0 & $12.1-20.9$ & 0.51 & $0.25-1.07$ \\
\hline Self-employed & 75681 & 12 & 16.5 & $8.0-30.9$ & 1.85 & $0.62-3.53$ \\
\hline \multicolumn{7}{|l|}{ Income level } \\
\hline Quintile 5 & 264141 & 45 & 23.6 & $16.9-32.0$ & Ref. & \\
\hline Quintile 4 & 156184 & 33 & 20.6 & $13.2-30.8$ & 1.28 & $0.65-2.54$ \\
\hline Quintile 3 & 121071 & 23 & 15.3 & $9.4-23.9$ & 0.75 & $0.35-1.63$ \\
\hline Quintile 2 & 79493 & 16 & 17.1 & $9.6-28.7$ & 0.86 & $0.32-2.34$ \\
\hline Quintile 1 & 10322 & 5 & 4.7 & $1.6-12.8$ & 0.41 & $0.12-1.42$ \\
\hline \multicolumn{7}{|l|}{ Marital status } \\
\hline Married & 378956 & 76 & 20.6 & $16.0-26.2$ & Ref. & \\
\hline Single & 248585 & 39 & 16.8 & $11.3-24.3$ & 1.67 & $0.83-3.39$ \\
\hline Widow(er)/divorced & 11641 & 9 & 14.0 & $5.3-31.8$ & 0.68 & $0.20-2.32$ \\
\hline \multicolumn{7}{|l|}{ Smoking status } \\
\hline Yes & 71726 & 10 & 5.0 & $2.1-11.4$ & Ref. & \\
\hline No & 567456 & 114 & 28.7 & $23.2-34.8$ & 32.26 & $15.38-66.66$ \\
\hline
\end{tabular}

\section{DISCUSSION}

The study found a significant association between the smoke-free legislation in the workplace and living in smoke-free homes in Malaysia. Our finding was consistent with the findings of other studies in other developed or developing countries. The longitudinal studies conducted by Edward et al. ${ }^{19}$ from 2003 to 2006 showed an increase in smoke-free homes from $64 \%$ to $70 \%^{19}$, in line with the decline of SHS exposure at workplaces from $20 \%$ to $8 \%$ following the expansion of the smoking ban at workplaces. Fong et al. ${ }^{20}$ also reported a reduction in home smoking rates from $85 \%$ to $80 \%$ after the implementation of comprehensive smoke-free legislation at workplaces. In addition, comparable positive results were generated from studies by Kaleta et al. ${ }^{16}$, Lee et al. ${ }^{17}$ and Nazar et al. ${ }^{18}$ among Nigerian, Indian and adults from 15 LMIC countries, respectively, in which respondents living in smoke-free homes were 5.3, 2.07, and 0.6 times, more likely to be among those employed in a totally smoke-free workplace compared to those in nonsmoke-free workplaces, after adjustment for potential confounders. Our findings might be explained by the 'Norm Spreading' in the life cycle model of social norms, as smoke-free norms developed and created from smoking prohibited workplaces may expand into other localities, more so in homes ${ }^{17,21,22}$. Another plausible reason might be due to those people who are against smoking and whose homes are smoke-free opting for smoke-free workplaces where available. 
However, future studies are strongly recommended to elucidate the factors contributed to the findings in our current study.

In our study, non-smokers were more likely to live in smoke-free homes. This finding is in line with Kaleta et al. ${ }^{16}$ and Thomas et al. ${ }^{23}$. It may be that non-smokers have a negative attitude towards smoking. This affects their behaviours, such as not allowing this practice in their homes. In addition, the smoking status may create non-permanent norms for other families to smoke in their homes. However, this aspect needs to be investigated in depth in future studies. In contrast to the findings by Nazar et al. ${ }^{18}$, our study found that female respondents were more likely to live in smokefree homes. The low prevalence of smoking among women in several studies conducted at the national level reduces their risk of SHS exposure. A similar explanation might be applied to the higher likelihood of ethnic Chinese living in smoke-free homes. However, the level of income, education level, marital status and living quarters were found to be insignificant in multivariate analyses after confounder effects were conveyed. These findings contradict the findings by Kaleta et al. ${ }^{16}$ and Berg et al. ${ }^{24}$ This may be due to proxy by education status, which does not lead to behavioural changes, as the health effects of exposure to SHS require a long period of time to show an impact. This aspect needs to be detailed in future studies.

Nevertheless, only $18.8 \%$ of the currently working respondents reported to be living in smoke-free homes. This figure was noticeably lower than the prevalence studies reported in China (21\%), Thailand ( $73 \%)$, and Mexico $(75 \%)^{18}$. We postulated that one possible explanation for this lower prevalence in Malaysia was most likely due to smoking being accepted as a normative behaviour among the Malaysian population. Therefore, they have a high tolerance towards smoking and SHS exposure that ultimately leads to widespread recognition of smoking and exposure of others to tobacco smoke as a norm. In addition, the habit of smoking has been accepted by the Malaysian society for ages whilst legislation on smoking restriction in the workplace has only been implemented recently. Thus, this might lead to a low rate of practising it $^{13}$. However, more profound investigation on this aspect should be carried out in future studies. Our findings also suggest that more aggressive measures and strategies are necessary to increase the proportion of smoke-free homes in Malaysia to be in line with the recommendations of Article 8, of the Framework Convention on Tobacco Control (FCTC), which urged all parties to set suitable initiatives to reduce secondhand smoke exposure in public places, working areas, and at home ${ }^{25}$. Future policies should focus on the generation of a smokefree environment in all workplaces, as our current smoke-free regulation primarily focuses on smoking prohibition only in certain premises such as health care facilities. There is also only one sub-regulation related directly to smoke-free working areas (i.e. smoking is prohibited in all working areas with central air-conditioning systems $)^{13}$.

\section{Limitations}

There are several limitations in this study. Firstly, the status of smoke-free homes and working areas were based on self-reported data. Therefore, it might be under or over reported due to recall bias. Secondly, this current cross-sectional study in which both variables (smoke-free workplaces and smokefree homes) are measured simultaneously limits the causal interpretation of our findings. For example, we cannot ascertain whether having workplace policies influences the adoption of smoke-free homes or those living in smoke-free homes chose to work in smokefree workplaces. To address this, a longitudinal study on tobacco use and exposure among Malaysian adults should be carried out ${ }^{26}$.

Lastly, a substantial proportion of our respondents did not respond to an item to measure the dependent variable (i.e. living in smoke-free homes). This might affect the overall results. However, the analysis in this study had controlled for several potential confounding factors including education, gender, smoking status, and geographical location, hence, enhancing the validity of our findings. In addition, our study had a large sample size of the representative sample that enabled the findings to be generalized to the Malaysian population. Furthermore, our study employed the standard protocol and tools recommended in GATS nationwide, allowing a standard comparison with other countries using similar protocols and tools.

\section{CONCLUSIONS}

Our present study demonstrates that the proportion of smoke-free homes reported among working Malaysian 
adults was small and remained non-prevalent nationwide. Our study suggests that respondents working in smoking-restricted workplaces are more likely to live in smoke-free homes in Malaysia, which can ultimately reduce SHS exposure and improve the health status of the Malaysian population. Therefore, specially-tailored public health policies related to smoke-free environments in working areas are warranted. On the other hand, aggressive voluntary smoking restrictions at home could also potentially be achieved through the expansion of the communitybased health promotion and intervention program (KOSPEN - Komuniti Sihat, Pembina Negara Health community, Building the Nation) among the Malaysian community.

\section{REFERENCES}

1. Institute of Pubic Health. National Health and Morbidity Survey: Cigarette Smoking. Kuala Lumpur: Institute of Public Health; 1987.

2. Institute for Public Health. The Third National Health and Morbidity Survey - Smoking, 2006. Kuala Lumpur: Institute for Public Health; 2008.

3. Institute for Public Health. National Health and Morbidity Survey 1996 - Smoking. Kuala Lumpur: Institute of Public Health; 1997.

4. Lim HK, Ghazali SM, Kee CC et al. Epidemiology of smoking among Malaysian adult males: prevalence and associated factors. BMC Public Health. 2013;13(1):8. doi:10.1186/1471-2458-13-8

5. Lim KH, Teh CH, Pan S et al. Prevalence and factor/s associated with smoking among adults in Malaysia Findings from the National Health and Morbidity Survey (NHMS) 2015. Tob Induc Dis. 2018, 16(January):1-11. doi:10.18332/tid/82190

6. Institute for Public Health. National health and morbidity survey 2015 - Report on smoking status among Malaysian adults. Kuala Lumpur: Institute of Public Health; 2015. http://www.moh.gov.my/moh/resources/NHMS2015VolumeV.pdf. Accessed October 7, 2018.

7. Chen Z, Liu G, Chen J, Li S, Jiang T, Xu B, Ye X. Frequency-risk relationships between second-hand smoke exposure and respiratory symptoms among adolescents: a cross-sectional study in South China. BMJ Open. 2018;8(4):e019875. doi:10.1136/bmjopen-2017-019875

8. Oberg M, Jaakkola MS, Woodward A, Peruga A, PrussUstun A. Worldwide burden of disease from exposure to second-hand smoke: a retrospective analysis of data from 192 countries. Lancet. 2011;377(9760):139-146. doi:10.1016/s0140-6736(10)61388-8

9. Office on Smoking and Health (US). The health consequences of involuntary exposure to tobacco smoke: a report of the surgeon general. Atlanta (GA): Centers for Disease Control and Prevention (US); 2006. https:// www.ncbi.nlm.nih.gov/books/NBK44324/. Accessed October 7, 2018.

10. Andreeva TI, Krasovsky KS, Semenova DS. Correlates of smoking initiation among young adults in Ukraine: a cross-sectional study: BMC Public Health. 2007;7:106. doi:10.1186/1471-2458-7-106

11. Wang MP, Ho SY, Lo WS, Lam TH. Smoking family, secondhand smoke exposure at home, and quitting in adolescent smokers. Nicotine Tob Res. 2013;15(1):185191. doi:10.1093/ntr/nts109

12. His Majesty Government gazette. [Food act 1983: Control of tobacco product Regulations]. 2005. http://www. tobaccocontrollaws.org/files/live/Malaysia/Malaysia\%20 -\%20TC\%20Regs\%202004.pdf. Accessed October 7, 2018.

13. Attorney General's Chambers. Control of tobacco product (amendment): Regulations 2012. http://www. tobaccocontrollaws.org/files/live/Malaysia/Malaysia $\% 20$ -\%20Dec.\%20of\%20Non-Smoking\%20Area\%202012.pdf. Accessed October 7, 2018.

14. Melaka Smoke Free Evaluation Project 2014. University of Waterloo, University Sains Malaysia, Melaka State Health Department; 2014.

15. Ministry of Human Resources. Guidelines on Occupational Safety and Health in the Office. Malaysia, Department of Occupational Safety and Health; 1996. http://www. dosh.gov.my/index.php/en/legislation/guidelines/ general/602-09-guidelines-on-occupational-safety-andhealth-in-the-office-1996/file. Accessed October 7, 2018.

16. Kaleta D, Polanska K, Usidame B. Smoke-Free Workplaces Are Associated with Protection from Second-Hand Smoke at Homes in Nigeria: Evidence for PopulationLevel Decisions. Biomed Res Int. 2015;(10):1-8. doi:10.1155/2015/618640

17. Lee JT, Agrawal S, Basu S, Glantz SA, Millett C. Association between smoke-free workplace and second-hand smoke exposure at home in India. Tob Control. 2014;23(4):308312. doi:10.1136/tobaccocontrol-2012-050817

18. Nazar GP, Lee JT, Glantz SA, Arora M, Pearce N, Millett C. Association between being employed in a smoke-free workplace and living in a smoke-free home: evidence from 15 low and middle income countries. Prev Med. 2014;59:47-53. doi:10.1016/j.ypmed.2013.11.017

19. Edwards R, Thomson G, Wilson N, et al. After the smoke has cleared: evaluation of the impact of a new national smoke-free law in New Zealand. Tob Control. 2008;17(1):e2. doi:10.1136/tc.2007.020347

20. Fong GT, Hyland A, Borland R, et al. Reductions in tobacco smoke pollution and increases in support for smoke-free public places following the implementation of comprehensive smoke-free workplace legislation in the Republic of Ireland: findings from the ITC Ireland/ UK Survey. Tob Control. 2006;15(Suppl 3):iii51-iii58. 
doi:10.1136/tc.2005.013649

21. Cheng KW, Glantz SA, Lightwood JM. Association between smokefree laws and voluntary smokefreehome rules. Am J Prev Med. 2011;41(6):566-572. doi:10.1016/j.amepre.2011.08.014

22. Monson E, Arsenault N. Effects of Enactment of Legislative (Public) Smoking Bans on Voluntary Home Smoking Restrictions: A Review. Nicotine Tob Res. 2017;19(2):141-148. doi:10.1093/ntr/ntw171

23. Thomas DP, Panaretto KS, Stevens M, Bennet PT, Borland R. Smoke-free homes and workplaces of a national sample of Aboriginal and Torres Strait Islander people. Med J Aust. 2015;202(Suppl 10):S33-S38. doi:10.5694/mja14.00876

24. Berg CJ, Daley CM, Nazir M et al. Smoke-Free Policies in the Workplace and in the Home among American Indians. J Health Dispar Res Pract. 2012;5(2):81-91. PMID: 23795333.

25. World Health Organization. WHO framework convention on tobacco control. Geneva, Switzerland: World Health Organization; 2003. [http://apps.who.int/iris/bitstream/ handle/10665/42811/9241591013.pdf;jsessionid= 0F 144 C 8 C 63925 C C 72327 D B D 9 BE 1 E 52 CA? sequence $=1$. Accessed October 7, 2018.

26. Faseru B, Cox LS, Opole I, Reed GA, Mayo MS, Ahluwalia JS, Okuyemi KS. Design, recruitment, and retention of African-American smokers in a pharmacokinetic study. BMC Med Res Methodol. 2010;10(1):6. doi:10.1186/1471-2288-10-6
ACKNOWLEDGEMENTS

We thank the Director General of Health, Malaysia for permission to publish this article. We would also like to thank those who were involved in the study and those who assisted in the collection and management of the data for their support and cooperation.

\section{CONFLICTS OF INTEREST}

The authors have completed and submitted the ICMJE Form for Disclosure of Potential Conflicts of Interest and none was reported.

\section{FUNDING}

The project was funded by the Ministry of Health, Malaysia.

PROVENANCE AND PEER REVIEW

Not commissioned; externally peer reviewed. 